\title{
Tuberculosis notification rate decreases faster in residents of native origin than in residents of foreign origin in the EU/EEA, 2010 to 2015
}

V Hollo ${ }^{1}$, J Beauté ${ }^{1}$, C Ködmön ${ }^{1}$, M van der Werf ${ }^{1}$

1. European Centre for Disease Prevention and Control (ECDC), Stockholm, Sweden

Correspondence: Vahur Hollo (vahur.hollo@ecdc.europa.eu)

To estimate trends in tuberculosis (TB) notification rates by geographical origin, we retrieved surveillance data from 2010 to 2015 for 29 European Union and European Economic Area countries. The TB notification rate decreased at an annual rate of $5.3 \%$. The decrease in notification rate was higher in native residents $(7.0 \%)$ than in those of foreign origin (3.7\%). Targeted screening and facilitated access to care and treatment could help prevent and control TB in migrants.

The tuberculosis (TB) notification rate in the European Union (EU) and European Economic Area (EEA) has been decreasing consistently since 2002 at an annual rate of around $5 \%$ [1]. In 2015, the EU/EEA notification rate was 11.7 per 100,000 population, close to the 'End TB 2035' target of less than 10 cases per 100,000 set by the World Health Organization (WHO) [2]. This encouraging figure masks important disparities both across and within countries. In 2015, rates were already below 10 per 100,000 in 22 countries but still above 50 per 100,000 in Lithuania and Romania [1]. Studies have also identified vulnerable groups for TB in low-incidence countries, such as prison inmates, people living with HIV, or migrants [3]. Here, we report TB notification rate trends for both native and foreign residents of the EU/EEA and assess progress towards TB elimination by predicting TB notification rates to 2025 .

\section{Tuberculosis surveillance in the EU/EEA}

The surveillance of TB in Europe is carried out by the European Tuberculosis Surveillance Network under the joint coordination of the European Centre for Disease Prevention and Control (ECDC) and the WHO. Each year, $30 \mathrm{EU} / \mathrm{EEA}$ countries upload all TB cases meeting the EU case definition [4] to a database hosted by ECDC (the European Surveillance System, TESSy). Information collected includes main epidemiological (time, place, sex, age, patient origin) and case management variables such as laboratory results or treatment outcome. A more detailed description of data collection methods is available elsewhere [1]. In most EU/EEA countries, a TB case of foreign origin is a case with a country of birth different from the reporting country. For Austria, Belgium, Greece, Hungary and Poland, a TB case of foreign origin is a case with citizenship different from the reporting country. For the purpose of this analysis, we included all TB cases reported for the period from 2010 to 2015. Data for Croatia were excluded because case-based data were only available from 2012 onwards.

\section{Population data and analysis}

We obtained population denominator data by origin from the Statistical Office of the European Union (Eurostat) [5]. We used population by country of birth for most countries and population by citizenship for Austria, Belgium, Greece, Hungary and Poland. Where population data were missing (Bulgaria in 2010 and Norway in 2015), we used the data of the year after for Bulgaria and the year before for Norway. We estimated annual rates of change by origin and their $95 \%$ confidence intervals $(\mathrm{Cl})$ using a log-linear regression of notification rates over the period 2010 to 2015. Assuming constant rates of decrease, we estimated notification rates by origin until 2025. We did not forecast until 2035 (target year of the End TB strategy) because only six years of denominator data were available.

\section{Trends}

Over the period from 2010to 2015, 29 countries reported 404,551 TB cases, of which 394,110 (97.4\%) had information on origin. Of these 394,110 cases, $283,426(71.9 \%)$ were born in or citizens of the reporting country and $110,684(28.1 \%)$ were of foreign origin (Table).

The proportion of cases of foreign origin continuously increased from $25.9 \%$ in 2010 to $31.1 \%$ in 2015 . Over the same period, the proportion of EU residents of foreign origin remained stable at $9.4 \%$ in 2010 and $10.0 \%$ 


\section{FIGURE}

Notification rate of tuberculosis cases per 100,000 population, by year and origin, EU/EEA, 2010-2015, and prediction for 2016-2025

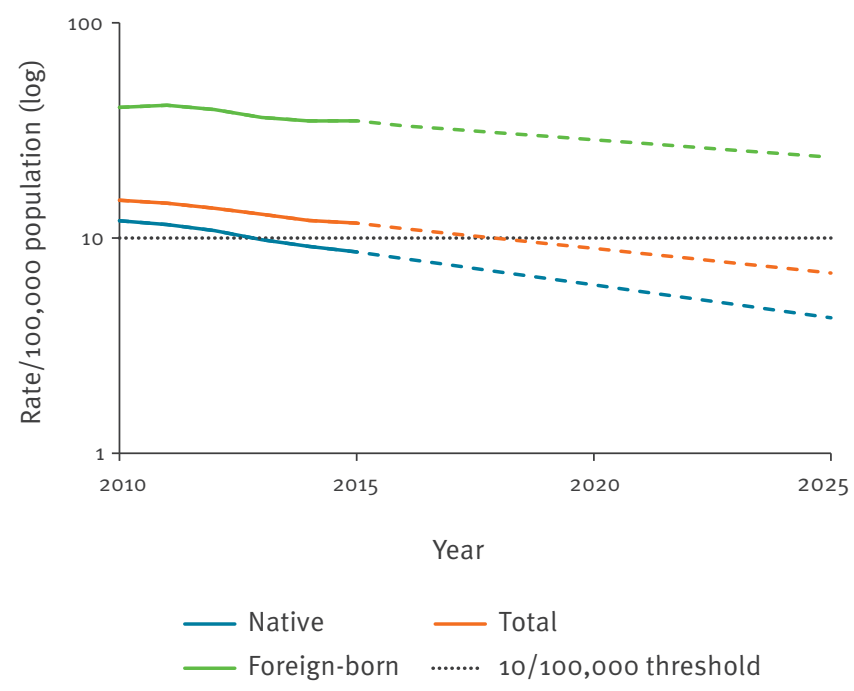

EU/EEA: European Union/European Economic Area.

Solid lines: rates calculated from reported cases; dotted lines: estimated prediction.

in 2015. Overall, the TB notification rate decreased at an annual rate of $5.3 \%$ (95\% Cl: 4.4-6.1) over the study period. This decrease was more pronounced in native residents $(7.0 \%, 95 \% \mathrm{Cl}: 6.0-8.0)$ than in cases of foreign origin $(3.7 \%, 95 \% \mathrm{Cl}: 1.7-5.8)$. The rate ratio of TB cases of foreign origin over native residents increased from 3.4 in 2010 to 4.1 in 2015 . Assuming that similar decreases in notification rates would be observed in the following years, the overall TB notification rate would cross the 10 per 100,000 threshold by 2018 (Figure).

By 2025 , the estimated notification rate in native residents would be at 4.3 per 100,000, approaching the pre-elimination target of less than 1 case per 100,000 [3]. However, the notification rate in cases of foreign origin would still be higher than 20 cases per 100,000.

\section{Discussion}

The TB notification rate is decreasing in the EU/EEA, but the pace differs depending on cases' geographical origin. Residents of foreign origin have a three- to fourfold higher notification rate compared with natives. This was observed in most countries except Bulgaria, Hungary, Latvia, Lithuania, Poland and Romania, where higher TB notification rates were reported in natives. Studies have suggested that TB rates in migrants are strongly associated with the incidence in their country of origin $[6,7]$. It is therefore not surprising to observe high rates of TB in residents of foreign origin in some EU/EEA countries because a considerable proportion of them originate from high-TB-incidence countries [8].
Since 2000, TB incidence has also been decreasing globally but at a slower rate than in EU/EEA countries [2]. Thus, TB cases of foreign origin are and will remain a challenge for TB elimination, especially in low-incidence countries where they account for a substantial proportion of TB cases [9].

The main reason explaining the higher TB burden in residents of foreign origin in high-income countries is thought to be reactivation of remotely acquired latent tuberculosis infection [10]. This does not exclude other possible explanations such as travel-associated infection when visiting friends or relatives in the country of origin [11] or infection in the receiving country where migrants may face poor living conditions. The latter two reasons could also partly explain why also secondgeneration migrants may be at higher risk for TB infection compared with native residents [12].

The main limitation of this analysis is that we classified all cases with a birthplace different from the reporting country as cases of foreign origin regardless of their time of arrival or the duration of their stay in the receiving countries. Also, we were not able to distinguish between migrants from low- and high-TB incidence countries. Characteristics of migrants and travellers are of increasing complexity which is challenging to capture through binary variables. Global travel and migration patterns have changed and intra-regional migration has increased [8]. Migrants may have stayed in other countries on their journey to the receiving country and been exposed to TB in other places than their country of origin. Estimates at EU/EEA level may mask important disparities across countries in which patterns of migration differ.

To address the challenge of TB among migrants in lowincidence countries, targeted prevention and control strategies should be implemented taking into account the origin of migrants but also their demographic characteristics. As most cases of foreign origin are likely to have been infected in their country of origin, preventive strategies in the host countries may have limited impact on the overall notification rate. A recent review suggested that targeted pre-arrival screening for active TB and post-arrival screening for latent TB infection in migrants would be the most efficient strategy [10]. Strategies reaching migrants arriving through irregular channels should also be explored.

\section{Conclusion}

The TB notification rate in individuals of foreign origin reported by EU/EEA countries is higher, and decreasing at a slower pace, than in native residents. This will be one of the main challenges for EU/EEA countries when trying to reach the TB elimination target in the coming years, especially in countries where individuals of foreign origin account for a large proportion of TB cases. Targeted screening and facilitated access to care and treatment could help tackle this issue. 


\begin{tabular}{|c|c|c|c|c|c|c|c|c|c|c|}
\hline \multirow{2}{*}{ Year } & \multicolumn{3}{|c|}{ Native } & \multicolumn{3}{|c|}{ Foreign origin } & \multirow{2}{*}{$\begin{array}{c}\text { Unknown } \\
\text { origin }^{\text {b }}\end{array}$} & \multicolumn{3}{|c|}{ Total } \\
\hline & Cases & $\begin{array}{l}\text { Population } \\
\text { (million) }\end{array}$ & Rate & Cases & $\begin{array}{l}\text { Population } \\
\text { (million) }\end{array}$ & Rate & & Cases & $\begin{array}{l}\text { Population } \\
\text { (million) }\end{array}$ & Rate \\
\hline 2010 & 54,956 & 456.9 & 12.0 & 19,242 & 47.5 & 40.5 & 1,376 & 75,574 & 504.4 & 15.0 \\
\hline 2011 & 52,753 & $457 \cdot 3$ & 11.5 & 19,504 & 47.1 & 41.4 & 1,045 & 73,302 & 504.4 & $14 \cdot 5$ \\
\hline 2012 & 49,498 & 457.4 & 10.8 & 19,038 & 48.2 & 39.5 & 994 & 69,530 & 505.6 & 13.8 \\
\hline 2013 & 44,877 & 456.7 & 9.8 & 17,742 & 48.9 & 36.3 & 2,549 & 65,168 & 505.5 & 12.9 \\
\hline 2014 & 41,870 & 457.8 & 9.1 & 17,319 & $49 \cdot 5$ & 35.0 & 2,079 & 61,268 & 507.3 & 12.1 \\
\hline 2015 & 39,472 & 458.0 & 8.6 & 17,839 & 50.9 & 35.1 & 2,398 & 59,709 & 508.9 & 11.7 \\
\hline
\end{tabular}

EU/EEA: European Union/European Economic Area.

a Croatia excluded.

${ }^{b}$ Without denominator, rates were not calculated for cases of unknown origin.

\section{Acknowledgements}

The authors acknowledge the nominated national operational contact points for tuberculosis Peter Henrik Andersen, Trude Margrete Arnesen, Bernhard Benka, Thorsteinn Blondal, Colin Campbell, Domnica Ioana Chiotan, Edita Davidavičienè, Raquel Duarte, Lena Fiebig, Jean-Paul Guthmann, Jerker Jonsson, Ourania Kalkouni, Maria Koliou, Maria Korzeniewska - Kosela, Gábor Kovács, Francesco Paolo Maraglino, Dace Mihalovska, Joan O’Donnell, Analita Pace Asciak, Laura Sanchez-Cambronero Cejudo, Erika Slump, Hanna Soini, Ivan Solovič, Petra Svetina, Tonka Varleva, Piret Viiklepp, Jiři Wallenfels, Maryse Wanlin and Pierre Weicherding (names are in alphabetical order) for providing the surveillance data used in this analysis.

\section{Conflict of interest}

None declared.

\section{Authors' contributions}

Vahur Hollo coordinated the data analysis, wrote the manuscript and contributed to the study design. Julien Beauté drafted parts of the manuscript, contributed to the study design, revision of the manuscript and data analysis. Csaba Ködmön contributed to the data analysis and revision of the manuscript. Marieke Johanna van der Werf contributed to the design of the study, interpreted the results and revised the manuscript.

\section{References}

1. European Centre for Disease Prevention and Control (ECDC)/ World Health Organization Regional Office for Europe. Tuberculosis surveillance and monitoring in Europe 2017. Stockholm: ECDC; 2017. Available from: http://ecdc.europa.eu/ en/publications/Publications/ecdc-tuberculosis-surveillancemonitoring-Europe-2017.pdf

2. World Health Organization (WHO). Global tuberculosis report 2015. Geneva: WHO; 2015. Available from: http://www.who.int/ tb/publications/global_report/gtbr15_main_text.pdf?ua=1

3. World Health Organization (WHO). Framework towards tuberculosis elimination in low-incidence countries. Geneva: WHO; 2014. Available from: http://www.who.int/tb/ publications/elimination_framework/en/

4. European Commission. Commission Implementing Decision 2012/506/EU of 8 August 2012 amending Decision 2002/253/ EC laying down case definitions for reporting communicable diseases to the Community network under Decision No 2119/98/EC of the European Parliament and of the Council. Luxembourg: Official Journal of the European Union; L262/1. Available from: http://eur-lex.europa.eu/LexUriServ/ LexUriServ.do?uri=0J:L:2012:262:0001:0057:EN:PDF

5. Eurostat. Population (demo_pop). Luxembourg: Eurostat. [Accessed: 14 Dec 2016]. Available from: http://ec.europa.eu/ eurostat/cache/metadata/en/demo_pop_esms.htm

6. Aldridge RW, Zenner D, White PJ, Williamson EJ, Muzyamba MC, Dhavan P, et al. Tuberculosis in migrants moving from high-incidence to low-incidence countries: a populationbased cohort study of 519955 migrants screened before entry to England, Wales, and Northern Ireland. Lancet. 2016;388(10059):2510-8. DOI: 10.1016/S0140-6736(16)31008-X PMID: 27742165

7. Watkins RE, Plant AJ, Gushulak BD. Tuberculosis rates among migrants in Australia and Canada.Int J Tuberc Lung Dis. 2002;6(7):641-4.PMID: 12102305

8. Eurostat. People in the EU: who are we and how do we live? Luxembourg; Eurostat; 2015. Available from: http://ec.europa. eu/eurostat/documents/3217494/7089681/KS-04-15-567-EN-N . pdf/8b2459fe-oe4e-4bb7-bca7-7522999c3bfd

9. Ködmön C, Zucs P, van der Werf MJ. Migration-related tuberculosis: epidemiology and characteristics of tuberculosis cases originating outside the European Union and European Economic Area, 2007 to 2013. Euro Surveill. 2016;21(12):30164. DOI: 10.2807/1560-7917.ES.2016.21.12.30164 PMID: 27039665

10. Pareek M, Greenaway C, Noori T, Munoz J, Zenner D. The impact of migration on tuberculosis epidemiology and control in high-income countries: a review.BMC Med. 2016;14(1):48. DOI: 10.1186/s12916-016-0595-5 PMID: 27004556

11. Kik SV, Mensen M, Beltman M, Gijsberts M, van Ameijden EJC, Cobelens FGJ, et al. Risk of travelling to the country of origin for tuberculosis among immigrants living in a low-incidence country. Int J Tuberc Lung Dis. 2011;15(1):38-43.PMID: 21276294

12. Marx FM, Fiebig L, Hauer B, Brodhun B, Glaser-Paschke G, Magdorf $\mathrm{K}$, et al. Higher rate of tuberculosis in second generation migrants compared to native residents in a metropolitan setting in western Europe. PLoS One. 2015;10(6):e0119693. DOI: 10.1371/journal.pone.0119693 PMID: 26061733

\section{License and copyright}

This is an open-access article distributed under the terms of the Creative Commons Attribution (CC BY 4.0) Licence. You may share and adapt the material, but must give appropriate credit to the source, provide a link to the licence, and indicate if changes were made.

This article is copyright of the authors, 2017. 